\title{
FACTORS CAUSING ANEMIA AMONG THE PATIENTS SUFFERING FROM EPILEPSY
}

\author{
Omer Sultan, Muhammad Khalid, Muhammad Hammad Athar* \\ Pak Emirates Military Hospital/National University of Medical Sciences (NUMS) Rawalpindi Pakistan, *Combined Military Hospital Malir/National University \\ of Medical Sciences (NUMS) Pakistan
}

\section{ABSTRACT}

Objective: To assess the presence of anemia in epileptics presenting at neurology department of Pak Emirates Military Hospital Rawalpindi.

Study Design: Comparative cross sectional study.

Place and Duration of Study: Neurology department, Pak Emirates Military Hospital Rawalpindi, from Oct to Dec 2018.

Methodology: One hundred and eighteen patients were included in this study. Diagnosis of epilepsy was made by the routine international guidelines by the consultant neurologist. Iron deficiency anemia was diagnosed on the basis of hemoglobin and ferritin levels. Gender of the patient, age, duration of epilepsy, education and poly-pharmacy were correlated with of iron deficiency anemia among the epileptics included in our study during the period of study.

Results: A total of 118 patients were included in the study. Forty nine (41.5\%) patients were male while 69 (58.5\%) epileptics were females in this study. Most common type of seizures was generalized followed by the partial seizures. Out of 118 patients of epilepsy, $44.9 \%$ showed the presence of iron deficiency anemia while $55.1 \%$ had no anemia. Duration of illness and poly-pharmacy were correlated significantly $(p$-value $<0.05)$ with the findings of iron deficiency anemia in the epileptic studied in the given time.

Conclusion: Epilepsy patients had high frequency of iron deficiency anemia. Special attention should be paid towards the patients with long duration of epilepsy or those with seizures controlled with more than one pharmacological agents.

Keywords: Anemia, Epilepsy, Socio-demographic factors.

This is an Open Access article distributed under the terms of the Creative Commons Attribution License (https://creativecommons.org/licenses/by-nc/4.0/), which permits unrestricted use, distribution, and reproduction in any medium, provided the original work is properly cited.

\section{INTRODUCTION}

Developing countries face the challenge of many deficiency disorders and iron deficiency anemia has been one of these disorders especially affecting the young female population of the developing countries ${ }^{1}$. Iron deficiency anemia is a hematopoietic or nutritional condition but it has been associated with various systemic illness including the renal, liver, autoimmune and endocrine disorders ${ }^{2-5}$.

Global mental health gap program includes those neuropsychiatric disorders which have been common in the community but come late for the treatment. Epilepsy is one of these disorders which demand the attention of clinicians as well as public health experts ${ }^{6,7}$. Epidemiologicall data from all parts of the world show that this disease has been prevalent globally ${ }^{8}$. Headache, anxiety and anemia are some of the non-seizure manifestations of this chronic disease ${ }^{9,10}$.

Previous research provides a very limited data regarding this association. Most of the studies done in this regard revolve around the pediatric population. Naseer et al, concluded that anemia and febrile seizures are closely linked to each other ${ }^{11}$. Majority of the

Correspondence: Dr Omer Sultan, Department of Medicine, Pak Emirates Military Hospital Rawalpindi Pakistan

Received: 17 May 2019; revised received: 05 Aug 2019; accepted: 16 Aug 2019 patients of epilepsy had comorbidities including anemia in an Indian study ${ }^{12}$. Pregnant women generated similar results and anemia was common among pregnant epileptics of Kerala ${ }^{13}$. Presence of anemia reducing the threshold of seizures is a widely discussed phenomenon nowadays. Iron deficiency anemiaif become long standing and remain un-addressed or under addressed may lead to worsening of epilepsy and making life of the patients miserable making them prone to fatigue, lethargy and other symptoms of anemia in addition to the seizures which they have already been facing 8,9 .

Epilepsy and iron deficiency anemia can be related to each other in number of ways and can make each other worse. Excitation and inhibition (E/I) mechanism which is crucial component of electrical activity of brain is altered in patients with iron deficiency of anemia. When this mechanism becomes faulty, result may be in the form of seizures ${ }^{14}$. More over antiepileptic drugs may also prone the patient towards development of different types of anemias ${ }^{15}$. Therefore one single mechanism can't be attributed to the coexistence of anemia and epilepsy ${ }^{9}$.

Ours is a third world country where neurology is an evolving specialty with limited number of clinicians so research and development has been a compromised area in this regard. Epidemiological surveys have been 
conducted in Pakistan, which show considerable prevalence of this disorder but not much attention has been paid to study the comorbid conditions with this illness including the anemia. We therefore took this initiative and planned to conduct this study with the rationale to look for the presence of anemia in epiletics presenting at neurology department of Pak Emirates Military Hospital Rawalpindi.

\section{METHODOLOGY}

This study was carried out at Neurology department of Pak Emirates Military Hospital Rawalpindi. Sample size was calculated by WHO sample size calculator ${ }^{10}$. Non probability Consecutive sampling technique was used to gather the sample. 2010 International League Against Epilepsy (ILAE) Commission report was sued to diagnose the cases of epilepsy presenting at neurology department during the given study period of October to December 2018. Eighteen years to sixty years was the inclusion criteria for the age of epileptic patients. Patients with psychogenic non epileptic fits, anemias prior to epilepsy, intellectual disability problems, dystonias and psychiatric disorders were excluded right from the start of this study. Pregnant orbreast feeding women, patients with B-12 or folate deficiency, had recent surgery, had NSAIDs abuse or any autoimmune disorder or which were substance users of any illicit substance were also not included in the study.

Ethical aspects of the study were catered for before the start of study. Ethical review board committee of PEMH Rawalpindi was approached to get the approval. After the formal approval this study was conducted at neurology unit of the hospital. Inclusion and exclusion criteria were strictly followed and patients were provided all the necessary details regarding the study and approval was taken from them before formal inclusion. All the relevant investigations were done on the venous sample which was taken in the morning after 10 hours of fasting. Complete blood count $(\mathrm{CBC})$, serum ferritin, Total iron binding capacity (TIBC), B-12 and folate levels were the investigations performed on the venous blood drawn from the patients. CBC was measured using a flow cytometer and an automated analyzer. Serum ferritin was measured using a radioimmunoassay method. As this was a correlational study, so social and demographic variables were also collected for the statistical analysis. A specialized proforma was designed before the start of this study to incorporate all the relevant factors in the study to look for their correlation with the presence of iron efficiency anemia among the epilepsy patients. Detailed history and general physical examination was performed to look for and exclude the patients with confounding variables. Iron deficiency anemia was defined as blood hemoglobin values of $<12 \mathrm{~g} / \mathrm{dl}$ and Serum ferritin levels $15 \mathrm{ng} / \mathrm{mL}^{11-13}$.

SPSS-23 software used to perform the statistical analysis for this study. Descriptive statistics were used at first phase as basic analysis. Pearson chi-square test was used to find the correlation of different variables with iron deficiency anemia among the target population. Odds ratio was calculated with $95 \%$ confidence interval. Association was considered as significant if $p$-value turned out to be $\leq 0.05$ in both the tests used.

\section{RESULTS}

One hundred and thirty six patients of epilepsy reported in neurology department during the study period which could be recruited in our study. After initial assessment and application of the criterion of inclusion and exclusion set for this study eighteen patients were excluded and did not undergo the investigations required for this study. One hundred and eighteen patients were included in the final analysis. Forty nine patients $(41.5 \%)$ were males and $69(58.5 \%)$ were females. Most common type of seizures was generalized followed by the partial seizures. Out of 118 patients of epilepsy, $44.9 \%$ showed the presence of iron deficiency anemia while $55.1 \%$ had no anemia. Long

Table-I: Characteristics of the study group and their hemoglobin levels.

\begin{tabular}{|c|c|c|c|}
\hline $\begin{array}{l}\text { Socio } \\
\text { Demographic } \\
\text { Factors } \\
\text { Total }\end{array}$ & $\begin{array}{c}\text { No Iron } \\
\text { Deficiency } \\
\text { Anemia } \\
\mathrm{n}(\%), 65(55.1)\end{array}$ & $\begin{array}{c}\text { Iron } \\
\text { Deficiency } \\
\text { Anemia } \\
\text { n (\%), } 53(44.9)\end{array}$ & $\begin{array}{c}p- \\
\text { value }\end{array}$ \\
\hline \multicolumn{4}{|l|}{ Age } \\
\hline $\begin{array}{l}\leq 30 \text { year } \\
30-60\end{array}$ & $\begin{array}{l}27(41.5) \\
38(58.5)\end{array}$ & $\begin{array}{c}21(39.6) \\
3260.4\end{array}$ & 0.833 \\
\hline \multicolumn{4}{|l|}{ Gender } \\
\hline $\begin{array}{l}\text { Male } \\
\text { Female }\end{array}$ & $\begin{array}{l}30(46.1) \\
35(53.9)\end{array}$ & $\begin{array}{l}19(35.8) \\
34(64.2)\end{array}$ & 0.257 \\
\hline \multicolumn{4}{|l|}{ Education } \\
\hline $\begin{array}{l}\leq 10 \text { years } \\
>10 \text { years }\end{array}$ & $\begin{array}{l}49(75.4) \\
16(24.6) \\
\end{array}$ & $\begin{array}{l}38(71.7) \\
15(28.3)\end{array}$ & 0.651 \\
\hline \multicolumn{4}{|l|}{ Poly-Pharmacy } \\
\hline $\begin{array}{l}\text { No } \\
\text { Yes }\end{array}$ & $\begin{array}{l}35(53.9) \\
30(46.1)\end{array}$ & $\begin{array}{l}14(26.4) \\
39(73.6)\end{array}$ & 0.002 \\
\hline \multicolumn{4}{|c|}{ Duration of Illness } \\
\hline $\begin{array}{l}\leq 5 \text { years } \\
>5 \text { years }\end{array}$ & $\begin{array}{c}62(95.4) \\
03(4.6)\end{array}$ & $\begin{array}{c}35(66.1) \\
18(33.9)\end{array}$ & $<0.001$ \\
\hline
\end{tabular}

duration of illness and poly-pharmacy were linked with the presence of iron deficiency anemia when chi- 
square was applied. After applying the logistic regression we found that same factors had significant association with the presence of iron deficiency anemia among the patients of epilepsy.

Table II: The correlated factors relating to presence of iron deficiency anemia among the patients of epilepsy: the binary logistic regression analysis.

\begin{tabular}{|c|c|c|c|c|}
\hline & \multirow{2}{*}{$\begin{array}{c}p- \\
\text { value }\end{array}$} & \multirow{2}{*}{$\begin{array}{l}\text { Odds } \\
\text { Ratio }\end{array}$} & \multicolumn{2}{|c|}{$\begin{array}{c}\text { Confidence } \\
\text { Interval }(95 \%)\end{array}$} \\
\hline & & & Lower & Upper \\
\hline \multicolumn{5}{|l|}{ Age } \\
\hline$\leq 30$ years & 0.778 & 0.883 & 0.37 & 2.10 \\
\hline \multicolumn{5}{|l|}{ Duration of Illness } \\
\hline$<5$ years & $<0.001$ & 14.222 & 3.56 & 56.79 \\
\hline \multicolumn{5}{|l|}{ Gender } \\
\hline Male & 0.385 & 1.485 & 0.61 & 3.62 \\
\hline \multicolumn{5}{|l|}{ Education } \\
\hline$\geq$ Matriculate & 0.207 & 0.533 & 0.20 & 1.41 \\
\hline \multicolumn{5}{|l|}{ Poly-Pharmacy } \\
\hline no Poly-pharmacy & 0.003 & 3.896 & 1.56 & 9.66 \\
\hline
\end{tabular}

\section{DISCUSSION}

Our results showed a high frequency of iron deficiency anemia in the epileptics. Association of anemia and epileptic fits have been under discussion in all parts of the world in the past as wellit-17. Epilepsy considered as a hardcore neurological disorder may have medical condition as a comorbid and anemia could be a common comorbid. Using routine laboratory technique, it was seen that $44.9 \%$ of our target population had anemia with iron deficiency and that included the patients of both genders of adult age group. Mental health problems leading to nutrition problems, use of multiple pharmacological agents and poor control of epilepsy have been few pathways which could lead to anemia among epileptics. They have been discussed in the studies done in the past on this subject ${ }^{11-13}$. Reason behind these may be related to physiology of anemia and seizures, chronicity of disease and side effects of some medications. Epileptics included in this study were patients of a developing country which have a lot of confounding variable pre-disposing them to anemia. Longitudinal studies and repeated assessments are required to differentiate iron deficiency anemia due to epilepsy or other factors.

Iron deficiency anemia is a multi-dimensional problem with physical, nutritional and physiological dimensions. Epilepsy or its treatment may prone the individual to develop the hematopoietic problems including the anemia. Patient, care givers and the physician had complete focus to manage the epilepsy and control the fits and no one usually bothers about the associated complains especially at the start of study. It has been seen in routine that anemia affects the life quality and normal blood indices are required for proper functioning of human body ${ }^{18}$. Treating neurologist or physician should treat epilepsy as a whole instead of just focusing on the seizure. Side effects of medications should also be taken into account and told to the patient in the start of the treatment.

Generalized seizures have been commonly encountered among the epileptics and past literature has shown this fact repeatedly 19,20 . Our study had similar findings in terms of type of seizures encountered by the patients. Generalized discharge in brain causing the seizures may be due to the deficiency of iron and related metabolite which may be a common pathway to anemia as well as the seizures. Female predominance was unique finding in our analysis as a study done locally in the recent past concluded that males have been affected more with this disease in our part of the world ${ }^{16}$.

If the patient is using more than one anti-epileptic or combination drugs he is more likely to suffer from hematological side effects including the iron deficiency anemia. Studies done in the recent past had ascertained this fact ${ }^{21,22}$. This association was supported by our study analysis and poly-pharmacy emerged as strong predictor of iron deficiency anemia.

Various studies in the past have produced results showing thatlonger duration of illness whether treated or untreated can have direct and indirect effects on the body which can give rise to various deficiencies including the anemia ${ }^{21,23}$. Our study results revealed that patients with long duration of illness had more chance of developing iron deficiency anemia as compared to patients with less duration of illness.

We had a strict inclusion and exclusion and criteria and all efforts were made to follow that during the course of our study. But still we had some limitations. Few common illnesses which were not made part of the exclusion criteria may also affect the blood indices and contribute to the finding of iron deficiency anemia. Moreover nutritional status of the individuals and social class was not studies along with other variables during the study. We belong to the third world country where nutrition status of most people is compromised. Therefore anemia especially iron deficiency anemia may be due to nutritional deficiency instead of epilepsy and related factors. Studies addressing these 
limitations may reveal more accurate results in future and strengthen our findings.

\section{CONCLUSION}

Epilepsy patients had high frequency of iron deficiency anemia. Special attention should be paid towards the patients with long duration of epilepsy or those with seizures controlled with more than one pharmacological agents.

\section{CONFLICT OF INTEREST}

This study has no conflict of interest to be declared by any author.

\section{REFERENCES}

1. Soofi S, Khan GN, Sadiq K, Ariff S, Habib A, Kureishy S et al. Prevalence and possible factors associated with anaemia, and vitamin B12 and folate deficiencies in women of reproductive age in Pakistan: analysis of national-level secondary survey data. BMJ Open 2017; 7(12): e018007-10.

2. Keivani Z, Mirzaei M, Mahmoudzadeh M, Etemadifar S, Avijgan. The relationship between migraine headache and iron deficiency anemia in patients referred to neurology clinic of Shahrekord University of Medical Sciences. IJN 2010; 23(64): 37-43.

3. Wimbley JTD, Graham DY. Diagnosis and management of iron deficiency anemia in the $21^{\text {st }}$ century. Therap Adv Gastroenterol 2011; 4(3): 177-84.

4. Gkamprela E, Deutsch M, Pectasides D. Iron deficiency anemia in chronic liver disease: etiopathogenesis, diagnosis and treatment. Ann Gastroenterol 2017; 30(4): 405-13.

5. Aoun M, Karam R, Sleilaty G, Antoun L, Ammar W. Iron deficiency across chronic kidney disease stages: Is there a reverse gender pattern? Barretti P, ed. PLoS One 2018; 13(1): e0191541-45.

6. Borsook D. Neurological diseases and pain. Brain 2012; 135(2): $320-44$.

7. Kim DW, Lee SK. Headache and Epilepsy. J Epilepsy Res 2017; 7(1): 7-15.

8. World Health Organization \& UNHCR.mhGAP Humanitarian Intervention Guide (mhGAP-HIG): Clinical Management of Mental, Neurological and Substance use Conditions in Humanitarian Emergencies. WHO; Geneva: 2015 [Internet]. Available at https://www.who.int/mental_health/publications/mhgap_hig /en/. [Assessed at: 20 Nov 2018]

9. Humayun A, Haq I, Khan FR, Azad N, Khan MM, Weissbecker I. Implementing mhGAP training to strengthen existing services for an internally displaced population in Pakistan. Global Mental
Health 2017; 4(1): e6-10.

10. Yousefichaijan P, Eghbali A, Rafeie M, Sharafkhah M, Zolfi M, Firouzifar M. The relationship between iron deficiency anemia and simple febrile convulsion in children. Journal of Pediatric Neurosciences 2014; 9(2): 110-14.

11. Naseer MR, Patra KC. Correlation of serum iron and serum calcium levels in children with febrile seizures. Int J Contemp Pediatr 2015; 2(1): 406-10.

12. Amudhan S, Gururaj G, Satishchandra P. Epilepsy in India II: Impact, burden, and need for a multisectoral public health response. Ann Indian Acad Neurol 2015; 18(1): 369-81.

13. Homas SV, Indrani L, Devi GC, Jacob S, Beegum J, Jacob PP, et al. Pregnancy in women with epilepsy: Preliminary results of Kerala registry of epilepsy and pregnancy. Neurol Ind 2001; 49(1): 60-66.

14. Rudy M, Mayer-Proschel M. Iron Deficiency Affects Seizure Susceptibility in a Time- and Sex-Specific Manner. Asn Neuro 2017; 9(6): 1759091417746521.

15. Ghamari TZ, Zare M, Habibabadi JM, Najafi MR. Antiepileptic drugs: a consideration of clinical and biochemical outcome in patients with epilepsy. Inter J Prev Med 2013; 4(Suppl 2): S33037.

16. Siddiqui F, Sultan T, Mustafa S, Siddiqui S, Ali S, Malik A, et al. Epilepsy in Pakistan: national guidelines for clinicians. Pak J Neurol Sci 2015; 10(3): 47-62.

17. Wimbley JTD, Graham DY. Diagnosis and management of iron deficiency anemia in the $21^{\text {st }}$ century. Therap Adv Gastroenterol 2011; 4(3): 177-84.

18. Lozoff B. Early iron deficiency has brain and behavior effects consistent with dopaminergic dysfunction. J Nutr 2011; 141(1): $740-46$.

19. Manford M. Recent advances in epilepsy. J Neurol 2017; 264(8): 1811-24.

20. Fiest KM, Sauro KM, Wiebe S, Patten SB, Kwon CS, Dykeman J, et al. Prevalence and incidence of epilepsy: A systematic review and meta-analysis of international studies. Neurol 2017; 88(3): 296-03.

21. Joshi R, Tripathi M, Gupta P, Gulati S, Gupta YK. Adverse effects \& drug load of antiepileptic drugs in patients with epilepsy: Monotherapy versus polytherapy. Ind J Med Res 2017; 145(3): 317-26.

22. Habib M, Khan SU, Hoque MA, Mondal BA, Hasan AT, Chowdhury RN et al. Antiepileptic drug utilization in Bangladesh: experience from Dhaka Medical College Hospital. BMC Res Notes 2013; 6(1): 473-76.

23. Duman P, Varoglu AO, Kurum E. The long-term prognosis of epilepsy patients with medically treated over a period of eight years in Turkey. Pak J Med Sci 2017; 33(4): 1007-12. 